there is a normal distribution,or as median [25-75 IQR] when there is an usual one.

Results: 27 patients were analysed $(14 \mathrm{~W} / 13 \mathrm{M})$. At the beginning of the IGIV the average age was $57.8 \pm 15.98$ and the vasculitis average development was 1.29 \pm 0.68 . The vasculitis ANCA subtypes were: a)granulomatosis with polyangiitis $(n=14 ; 51.8 \%)$, b)microscopic polyangiits $(n=9 ; 33.3 \%)$, c)eosinophilic granulomatosis with polyangiitis $(n=2 ; 7.4 \%)$, d) pulmonary-renal syndrome with ANCA positive $(n=1 ; 3.7 \%)$ and e) indeterminate vasculits ANCA positive $(n=1,3.7 \%)$ Previously to the treatment with IGIV, apart from steroids, they also received: cyclophosphamide $(n=12,44.4 \%)$, metotrexate $(n=6,22.2 \%)$, infliximab $(n=5$, $18.5 \%)$, rituximab $(n=4,14,8 \%)$, azatioprine $(n=3,11.1 \%)$, mycophenolate $(n=3$, $11.1 \%)$ and plasmapheresis $(n=1 ; 3.7 \%)$.

Refractioness $(n=18)$ and suspicious of infection $(n=9)$ were the reasons for the application of IGIV. The IGIV guideline was $0.4 \mathrm{~g} / \mathrm{kg} /$ day for 5 consecutive days. $66.6 \%$ received methylprednisolona IV concomitant $(0.5-1 \mathrm{~g} /$ day for 3 days). After a follow-up of $80 \pm 68$.four months we observed clinical and analytical improvement, as well as, in the activity indexes (TABLE). The majority of the side effects were lower and IGIV was suspended in just one patient due to severe effects of congestive heart disease.

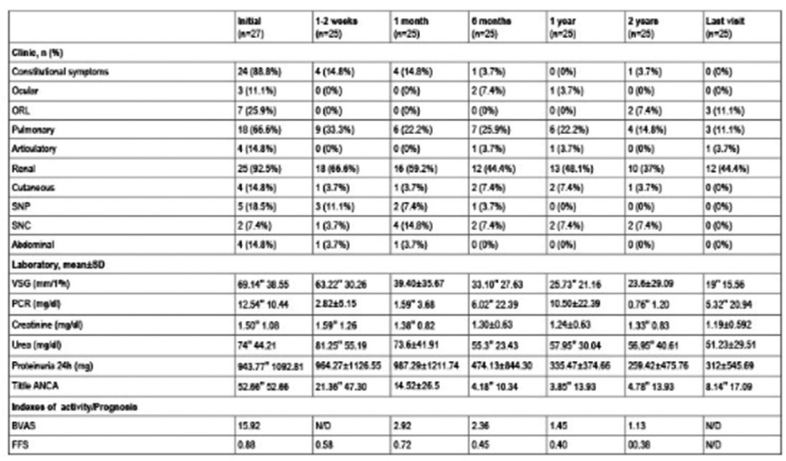

Conclusions: IGIV seems to be an effective and secure therapy in the treatment of vasculitis ANCA.

Acknowledgements: All members of Rheumatology

Disclosure of Interest: None declared

DOI: 10.1136/annrheumdis-2018-eular.4982

\section{SAT0541 INCIDENCE OF LARGE VESSEL GCA IN NORTHERN ITALY DURING A 12-YEAR PERIOD (2005-2016)}

$\underline{\text { P. Macchioni }}{ }^{1}$, L. Boiardi ${ }^{1}$, G. Restuccia ${ }^{1}$, F. Muratore ${ }^{1}$, P. Mancuso ${ }^{2}$, M. Catanoso ${ }^{1}$, C. Salvarani ${ }^{1}$. ${ }^{1}$ Ospedale Santa Maria Nuova; ${ }^{2}$ Epidemiology, Ausl Reggio Emilia, Reggio Emilia, Italy

Background: There are no studies regarding the incidence of large vessel GCA (LV GCA).

Objectives: To investigate the incidence of LVGCA in the Reggio Emilia Area from 2005 through to 2016 .

Methods: All patients with incident large vessel GCA diagnosed between 1 January 2005 and 31 December 2016 and living in the Reggio Emilia area, were identified by capture and re-capture checking of computerised discharge diagnosis codes (ICD10) and using outpatients databases from rheumatology, internal medicine, surgery, pathology, imaging departments of Reggio Emilia Hospital as well as by examining the Reggio Emilia district database for rare diseases. To be included in the study, patients must satisfy the following 2 criteria: Age at disease onset $\geq 50$ years; evidence of large-vessel vasculitis by angiography, MRA, CTA, $\mathrm{PET} / \mathrm{CT}$ and/or ultrasonography. We included in the study also patients associating biopsy proven GCA with evidence of LVV. We also evaluated the incidence of biopsy proven GCA without LV in same time period.

Results: There were 93 incident cases of LV GCA (66 women, 71\%) during the 12 year study period; Mean \pm SD age at diagnosis was $72 \pm 9$ years. Incidence per 100000 persons aged $\geq 50$ years was 3.78 (95\% confidence interval $[95 \% \mathrm{Cl}$ $3.01,4.55])$. In particular incidence was 1.60 in LV GCA with biopsy proven GCA and 2.18 in LV GCA not biopsy proven GCA (pts biopsy negative and pts in which the biopsy had not been performed). Incidence was significantly higher in women $(4.89[95 \% \mathrm{Cl} 3.69,6.09]$ than in men $(2.50[95 \% \mathrm{Cl} 1.56,3.45])(\mathrm{p}<0.0006)$. The highest incidence in women was observed in the 70-79 years age group (7.72 $[95 \% \mathrm{Cl} 4.89,11.58]$ while in men the peak of incidence was in the $80-89$ age group $(4.23$ [95\% $\mathrm{Cl} 2.50,8.45])$. A progressive increase in total incidence rates was observed during the 4 three years periods from $3.13(2005-2007)$ to 4.85 (2014-2016). The incidence per 100000 persons aged $\geq 50$ years of GCA biopsy proven without LV during the 12 year study period was $4.48[95 \% \mathrm{Cl}$ 2.22,9.45].

Conclusions: The incidence of LV GCA in the Reggio Emilia area 100.000/ aged $>50$ was 3.78 and it was lower than that of patients with biopsy proven GCA without LV; the incidence of LV GCA was significantly higher in women and increased during the study period.

\section{REFERENCE:}

[1] Catanoso M, et al. Arthritis Care Res (Hoboken) 2017 Mar;69(3):430-438.

Disclosure of Interest: None declared

DOI: 10.1136/annrheumdis-2018-eular.5197

\section{SAT0542 INTERLEUKIN-12 AND INTERLEUKIN-23 ARE KEY PATHOGENIC PLAYERS IN GIANT CELL ARTERITIS}

R. Conway ${ }^{1}$, L. O'Neill ${ }^{1}$, P. Gallagher ${ }^{1}$, G. McCarthy ${ }^{2}$, C. Murphy ${ }^{3}$, D. Veale ${ }^{1}$, U. Fearon ${ }^{4}$, E. Molloy ${ }^{1} .{ }^{1}$ St Vincents University Hospital; ${ }^{2}$ Mater Misericordiae University Hospital; ${ }^{3}$ Royal Victoria Eye and Ear Hospital; ${ }^{4}$ Trinity College Dublin, Dublin, Ireland

Background: Giant cell arteritis (GCA) is the most common form of systemic vasculitis; the pathogenesis is unclear. Current evidence suggests both the $T_{H} 1$ and $T_{H} 17$ pathways are important but the proximal initiators and effector cytokines are unknown. IL-12 and IL-23 secreted by dendritic cells are hypothesised as stimulators of these pathways. We have previously reported the efficacy of IL-12/23 blockade with ustekinumab in refractory GCA in a prospective clinical trial.

Objectives: To assess the role of IL-12 and IL-23 in GCA pathogenesis.

Methods: IL-12 and IL-23 were quantified by immunohistochemistry in tempora artery (TA) biopsies. TA explant, peripheral blood mononuclear cell (PBMC), and myofibroblast outgrowth culture models were established from patients with GCA and disease controls. PBMCs and TA explants were cultured for 24 hours in the presence or absence of IL-23 $(10 \mathrm{ng} / \mathrm{ml})$ or IL-12 $(50 \mathrm{ng} / \mathrm{ml})$. Gene expression was quantified by Real-time PCR and cytokine secretion by ELISA. Myofibroblast outgrowths were assessed following 28 days culture and quantified by counting the number of outgrowths/high-power field (hpf).

Results: Immunohistochemistry demonstrated IL-12p35 and IL-23p19 in inflammatory cells in TA biopsies ( $n=33$ ). IL-12p35 and IL-23p19 were only detected in positive TA biopsies. IL-12p35 was increased in those with cranial ischaemic com plications $(p=0.026)$ and those with large vessel vasculitis $(p=0.006)$. IL-23p19 was increased in those with two or more relapses $(p=0.007)$. In cultured PBMCs IL-12 stimulation increased IL-6 $(\mathrm{n}=17, \mathrm{p}=0.009), \mathrm{IL}-22(\mathrm{n}=16, \mathrm{p}=0.003)$, and IFN$\gamma(n=14, p=0.0001)$ secretion and decreased IL-8 $(n=15, p=0.0006)$ secretion, while IL-23 stimulation increased IL-6 ( $n=40, p=0.029), I L-22(n=16, p=0.001), I L-$ 17A $(n=16, p=0.0003)$ and IL-17F $(n=9, p=0.012)$ secretion. In the TA explant culture model, IL-23 stimulation increased gene expression of IL-8 $(n=13, p=0.0001)$ and CCL-20 $(n=9,0.027)$ and protein expression of IL-6 $(n=61, p=0.002)$ and IL-8 $(n=60, p=0.004)$, IL-12 stimulation $(n=14)$ had no effect; however, IFN- $\gamma$ and IL17A were not detectable in this model. IL-12 $(n=20, p=0.0005)$ and IL-23 $(n=33$, $p<0.0001$ ) stimulation increased the quantity of myofibroblast outgrowths from TA biopsies. In all experiments there were no significant differences between biopsy positive GCA, biopsy negative GCA, and disease controls.

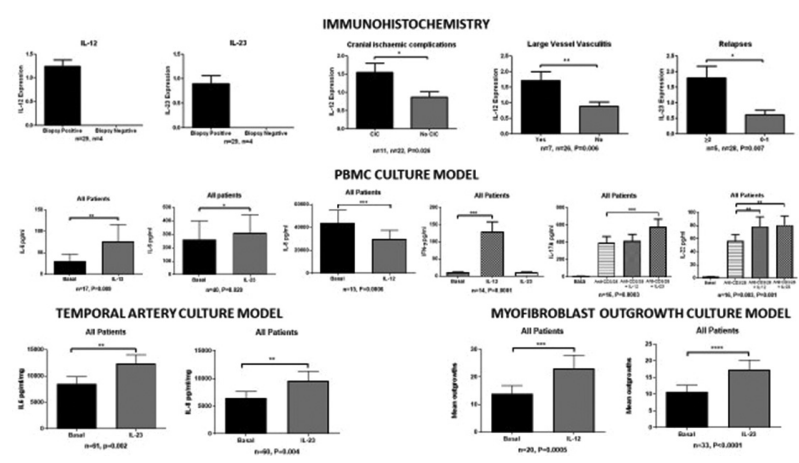

Conclusions: IL-12 and IL-23 play central and distinct roles in stimulating inflammatory and proliferative pathways in GCA. Our results were consistent in patients with biopsy positive and negative GCA, and in disease controls, suggesting that IL-12 and IL-23 play proximal roles in inducing these pathways.

Disclosure of Interest: None declared

DOI: 10.1136/annrheumdis-2018-eular.2850 